\title{
pH Neutralization Process Control based on Active Disturbance Rejection Control
}

\author{
Mohanad Hamad Eljack Elameen*, Mona Bahaeldin Musa Hago, Wen Tan \\ School of Control and Computer engineering, North China Electric Power University, 102206, China
}

\begin{tabular}{l} 
A R T I C L E I N F O \\
\hline Article history: \\
Received: 06 June, 2019 \\
Accepted: 16 August, 2019 \\
Online: 03 September, 2019 \\
\hline Keywords: \\
ADRC \\
Extended state observer (ESO) \\
rADRC \\
Nonlinear process \\
pH neutralization process
\end{tabular}

\begin{abstract}
A B S T R A C T
This paper considers active disturbance rejection control (ADRC) as a new control approach for $\mathrm{pH}$ neutralization process. The $\mathrm{pH}$ process is challenging to control due to its sensitivity to disturbance, nonlinear dynamics, and time-varying characteristics. Special attention is paid to the impact of disturbances typically exists in the chemical process. First, the $\mathrm{pH}$ neutralization process nonlinear model is presented, then the active disturbance rejection control is described briefly and a $\mathrm{pH}$ neutralization process closed-loop control system is designed on its bases, and investigated with simulation. More robust and better disturbance rejection performances are achieved compared to the control technique of feedback linearization $(F L)$.
\end{abstract}

\section{Introduction}

This paper is an extension of work presented initially in 2018 15th International Computer Conference on Wavelet Active Media Technology and Information Processing (ICCWAMTIP) [1]. Control of $\mathrm{pH}$ neutralization in the chemical and biotechnological industries is a typical process [2]. The $\mathrm{pH}$ of this effluent must be retained within environmental boundaries, before discharging the effluent streams from wastewater treatment plants. Tight $\mathrm{pH}$ control is also critically required in pharmaceutical production. However, owing to the high nonlinearity of the $\mathrm{pH}$ process, robust and high performance $\mathrm{pH}$ process control is often difficult to obtain [3-5]. The process gain of these processes can differ from a small range of $\mathrm{pH}$ values to several orders of magnitude. Thus it can exhibit severe static nonlinear behavior.

So far, many authors have proposed, developed, and implemented different control techniques to overcome this problem. The classical PID controller is the first technique applied to control the $\mathrm{pH}[6-8]$. In the field of industrial applications, the PID controller is considered as the most popular controller types, but it has been unable to satisfy the growing demand for efficiency, speed, and accuracy. Nonlinear control techniques also have been applied [9-21]. Other works involve intelligent control technique $[22,23]$. In general, most of the above methods require an adequate model, which could not be easy to obtain, add to that the complexity of the controller design based on the above approaches. Hence, $\mathrm{pH}$ neutralization process requires a new approach to control it.

\footnotetext{
*Mohanad Hamad Eljack Elameen, mohanadeljack@gmail.com www.astesj.com
}

https://dx.doi.org/10.25046/aj040513
In [24-26], Han introduced the powerful control technique active disturbance rejection control (ADRC) and simplified and identified in [27]. The states and disturbance can be estimated in the ADRC before an error can occur, which can ultimately attain early compensation and disturbance resistance. Since it was introduced, the ADRC method has gained worldwide attention and broad implementation and has become common after its linear form has appeared [28]. In many fields, ADRC has been implemented effectively, benefiting from its full control characteristics as fast system response, large scale adaptation, and small overshoot [29].

In this technique, a unique state observer is used to estimate what is called total disturbance. The uncertainties in the dynamics of the internal process and the disturbances of the output are considered as total disturbances. This observer is called the extended state observer (ESO), and it can track the state-space model's extended state, which can achieve this goal. The plant's state-space model should include only the model estimate. A linear model in a state-space form may be an estimate for a nonlinear system [29].

This work proposes a different control technique based on estimating the disturbances and actively rejecting it for $\mathrm{pH}$ neutralization process. All the disturbances typically presented in $\mathrm{pH}$ process are lumped together in one signal called total disturbances. The extended state observer tracks these disturbances and the control law cancels it.

The organization of this paper is as follows. The $\mathrm{pH}$ process's model is given in section 2 . Section 3 briefly presents the technique 
of feedback linearization. Section 4 shows the ADRC control system for the $\mathrm{pH}$ process. Section 5 gives the simulation results, and section 6 gives a general conclusion.

\section{Model of pH Process}

Figure 1 shows a schematic diagram describing the $\mathrm{pH}$ process. The process consists of an acid flow rate $\left(\mathrm{q}_{1}\right)$, buffer flow rate $\left(\mathrm{q}_{2}\right)$, and the base flow rate $\left(\mathrm{q}_{3}\right)$ mixed in the tank. $\mathrm{pH}_{4}$ represents the output of the process, where $\mathrm{q}_{3}$ represents the control input. By using the conservation equations of the reaction invariants and equilibrium relations, a dynamic model has been derived. Set tank volume $(V)$, Ideal mixing, constant density, and full ion solubility are considered as assumptions for modeling. The system's chemical reactions are:

$\mathrm{H}_{2} \mathrm{CO}_{3} \leftrightarrow \mathrm{HCO}_{3}^{-}+\mathrm{H}^{+}$,

$\mathrm{HCO}_{3}^{-} \leftrightarrow \mathrm{CO}_{3}^{2-}+\mathrm{H}^{+}$,

$\mathrm{H}_{2} \mathrm{O} \leftrightarrow \mathrm{OH}^{-}+\mathrm{H}^{+}$

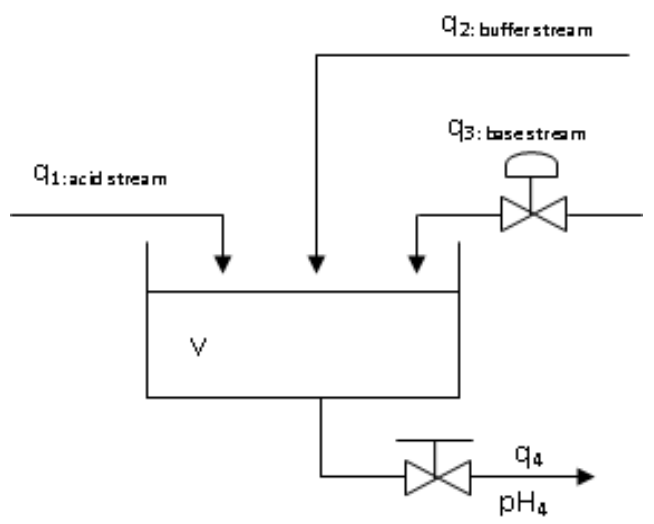

The reaction's equilibrium constants are

$K_{a 1}=\frac{\left[\mathrm{HCO}_{3}^{-}\right]\left[\mathrm{H}^{+}\right]}{\left[\mathrm{H}_{2} \mathrm{CO}_{3}\right]}$,

$K_{a 2}=\frac{\left[\mathrm{CO}_{3}^{2-}\right]\left[\mathrm{H}^{+}\right]}{\left[\mathrm{HCO}_{3}^{-}\right]}$,

$K_{w}=\left[\mathrm{H}^{+}\right]\left[\mathrm{OH}^{-}\right]$

The chemical balance is formed using the reaction invariant concept [30]. The invariants concentrations are $(i=1,2,3,4)$ :

$W_{a i}=\left[\mathrm{HCO}_{3}^{-}\right]_{i}+\left[\mathrm{H}^{+}\right]_{i}-2\left[\mathrm{CO}_{3}^{2-}\right]_{i}-\left[\mathrm{OH}^{-}\right]_{i}$

$W_{b i}=\left[\mathrm{HCO}_{3}^{-}\right]_{i}+\left[\mathrm{CO}_{3}^{2-}\right]_{i}+\left[\mathrm{H}_{2} \mathrm{CO}_{3}\right]_{i}$,

where $\mathrm{W}_{\mathrm{ai}}$ is a charge-related quantity, and $\mathrm{W}_{\mathrm{bi}}$ is the carbonate ion concentration, and they are independent of the extent of the reaction. The concentration of the hydrogen ion is calculated from:
$W_{a i}+W_{b i} \frac{\frac{K_{a 1}}{\left[H^{+}\right]_{i}}+\frac{2 K_{a 1} K_{a 2}}{\left[H^{+}\right]_{i}^{2}}}{1+\frac{K_{a 1}}{\left[H^{+}\right]_{i}}+\frac{K_{a 1} K_{a 2}}{\left[H^{+}\right]_{i}^{2}}}+\frac{K_{w}}{\left[H^{+}\right]_{i}}-\left[H^{+}\right]_{i}=0$.

The hydrogen ion $\left[\mathrm{H}^{+}\right]_{4}$ with the following relationship calculates the $\mathrm{pH}$ of the effluent stream:

$p H_{4}=-\log _{10}\left(\left[\mathrm{H}^{+}\right]_{4}\right)$

The dynamic model is given by the vessel's material balance:

$V \frac{d W_{a 4}}{d t}=q_{1}\left(W_{a 1}-W_{a 4}\right)+q_{2}\left(W_{a 2}-W_{a 4}\right)+q_{3}\left(W_{a 3}-W_{a 4}\right)$,

$V \frac{d W_{b 4}}{d t}=q_{1}\left(W_{b 1}-W_{b 4}\right)+q_{2}\left(W_{b 2}-W_{b 4}\right)+q_{3}\left(W_{b 3}-W_{b 4}\right)$.

This put the process model in a state-space form as

$$
\dot{X}=f(x)+g(x) u+p(x) d
$$

where

$$
\begin{aligned}
& u=q_{3}, \quad x=\left[\begin{array}{ll}
W_{a 4} & W_{b 4}
\end{array}\right]^{T}, \quad d=\left[\begin{array}{ll}
W_{a 1} & W_{b 1}
\end{array}\right]^{T}, \\
& f(x)=\left[\begin{array}{c}
-\frac{q_{1}}{V} x_{1}+\frac{q_{2}}{V}\left(W_{a 2}-x 1\right) \\
-\frac{q_{1}}{V} x_{2}+\frac{q_{2}}{V}\left(W_{b 2}-x 2\right)
\end{array}\right], \\
& g(x)=\left[\begin{array}{l}
\frac{1}{V}\left(W_{a 3}-x 1\right) \\
\frac{1}{V}\left(W_{b 3}-x 2\right)
\end{array}\right], \quad p=\left[\begin{array}{ll}
\frac{q_{1}}{V} & 0 \\
0 & \frac{q_{1}}{V}
\end{array}\right] .
\end{aligned}
$$

Note that Eq. (1) is linear in p, and the unknown parameters are presented in the vector $d$. The relation between the state variables $\mathrm{x}$ and the output $\mathrm{y}$ is nonlinear as shown by

$$
c(x, y)=0 \text {, }
$$

where

$$
\begin{gathered}
c(x, y)=x_{1}+10^{y-14}-10^{-y}+x_{2} c_{x 2}, \\
c_{x 2}=\frac{1+2 \times 10^{y-p k_{2}}}{1+10^{p k_{1}-y}+10^{y-p k_{2}}} \\
p k_{1}=-\log _{10} k_{a 1}, \quad p k_{2}=-\log _{10} k_{a 2} .
\end{gathered}
$$

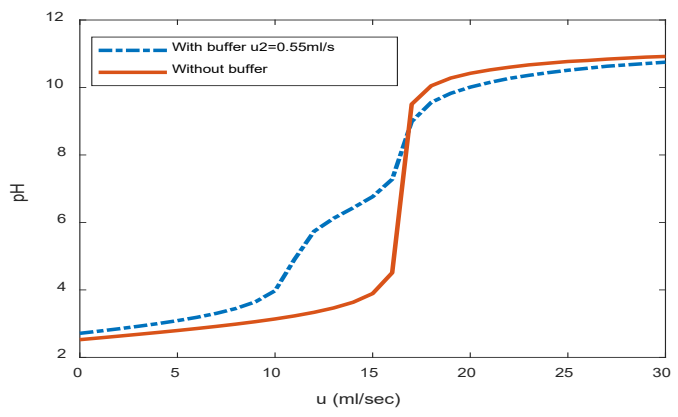

Figure 2: The dynamics of the $\mathrm{pH}$ process 
Table 1 shows the nominal values of the parameters.

Table 1. Model Parameters Nominal Values

\begin{tabular}{|l|l|}
\hline Parameter & Nominal value \\
\hline $\mathrm{V}$ & $2900 \mathrm{ml}$ \\
\hline $\mathrm{K}_{\mathrm{a} 1}$ & $4.47 \times 10^{-7}$ \\
\hline $\mathrm{K}_{\mathrm{a} 2}$ & $5.62 \times 10^{-11}$ \\
\hline$\left[\mathrm{q}_{1}\right]$ & $0.003 \mathrm{M} \mathrm{HNO} 3$ \\
\hline & $5 \times 10^{-5} \mathrm{M} \mathrm{H} 2 \mathrm{CO} 3$ \\
\hline$\left[\mathrm{q}_{2}\right]$ & $0.03 \mathrm{M} \mathrm{NaHCO} 3$ \\
\hline$\left[\mathrm{q}_{3}\right]$ & $0.003 \mathrm{M} \mathrm{NaOH}$ \\
\hline & $5 \times 10^{-5} \mathrm{M} \mathrm{NaHCO} 3$ \\
\hline $\mathrm{q}_{1}$ & $16.6 \mathrm{ml} / \mathrm{s}$ \\
\hline $\mathrm{q}_{2}$ & $0.55 \mathrm{ml} / \mathrm{s}$ \\
\hline $\mathrm{q}_{3}$ & $15.8 \mathrm{ml} / \mathrm{s}$ \\
\hline $\mathrm{pH}$ & 7.00 \\
\hline $\mathrm{W}_{\mathrm{a} 1}$ & $0.003 \mathrm{M}$ \\
\hline $\mathrm{W}_{\mathrm{b} 1}$ & $5 \times 10^{-5} \mathrm{M}$ \\
\hline $\mathrm{W}_{\mathrm{a} 2}$ & $-0.03 \mathrm{M}$ \\
\hline $\mathrm{W}_{\mathrm{b} 2}$ & $0.03 \mathrm{M}$ \\
\hline $\mathrm{W}_{\mathrm{a} 3}$ & $-3.05 \times 10^{-3} \mathrm{M}$ \\
\hline $\mathrm{W}_{\mathrm{b} 3}$ & $5 \times 10^{-5} \mathrm{M}$ \\
\hline $\mathrm{W}_{\mathrm{a} 4}$ & $-4.50 \times 10^{-4} \mathrm{M}$ \\
\hline $\mathrm{W}_{\mathrm{b} 4}$ & $5.5 \times 10^{-4} \mathrm{M}$ \\
\hline & \\
\hline
\end{tabular}

Figure 2 shows the static dynamics of the $\mathrm{pH}$ process, which shows strong nonlinearity.

\section{Feedback Linearization Technique}

For the severely nonlinear system expressed in (1-3), a nonlinear controller based on feedback linearization (FL) technique is first designed.

Consider the following nonlinear system

$$
\dot{\mathrm{x}}=\mathrm{f}(\mathrm{x})+\mathrm{g}(\mathrm{x}) \mathrm{u}, \quad \mathrm{y}=\mathrm{h}(\mathrm{x})
$$

The objective is to find a linear differential relation between a new input $\mathrm{v}$ and the output $\mathrm{y}$. The system has a relative degree $\mathrm{r}$ if

$$
\mathrm{L}_{\mathrm{g}} \mathrm{L}_{\mathrm{f}}^{\mathrm{i}}=0 \quad 0 \leq \mathrm{i} \leq \mathrm{r}-2
$$

$\mathrm{L}_{\mathrm{g}} \mathrm{L}_{\mathrm{f}}^{\mathrm{r}-1} \mathrm{~h}(\mathrm{x}) \neq 0$

where $\mathrm{Lf}$ in the direction of $\mathrm{f}$ is the Lie derivative. Suppose the system above has a relative degree of $r$ and is linearizable, then the input transformation

$$
u=\frac{v-\mathrm{L}_{f}^{r} h}{\mathrm{~L}_{g} \mathrm{~L}_{f}^{r-1} h}
$$

hence, the relation between $\mathrm{y}$ and $\mathrm{v}$ is linear as

$$
y^{(r)}=v
$$

For the $\mathrm{pH}$ process, by differentiating (3) using (1) we get

$$
\dot{y}=-c_{y}^{-1}(x, y) c_{x}(y)[f(x)+g(x) u+p(x) d]
$$

where

$$
\begin{aligned}
& \mathrm{c}_{\mathrm{x}}=\frac{\partial \mathrm{c}(\mathrm{x}, \mathrm{y})}{\partial \mathrm{x}}=\left[\begin{array}{ll}
\mathrm{c}_{\mathrm{x} 1} & \mathrm{c}_{\mathrm{x} 2}
\end{array}\right], \\
& \mathrm{c}_{\mathrm{x} 1}=1, \\
& \mathrm{c}_{\mathrm{x} 2}=\frac{1+2 \times 10^{\mathrm{y}-\mathrm{pk}_{2}}}{1+10^{\mathrm{pk}_{1}-\mathrm{y}+10^{\mathrm{y}-\mathrm{pk}}} .} \\
& \mathrm{c}_{\mathrm{y}}=(\ln 10) \times\left\{\mathrm{x}_{2}\left(\frac{10^{\mathrm{pk}_{1}-\mathrm{y}}+10^{\mathrm{y}-\mathrm{pk}_{2}}+4 \times 10^{\mathrm{pk}_{1}-\mathrm{pk}_{2}}}{\left(1+10^{\mathrm{pk}_{1}-\mathrm{y}}+10^{\mathrm{y}-\mathrm{pk}_{2}}\right)^{2}}\right)\right. \\
& \left.\quad+10^{\mathrm{y}-14}+10^{-\mathrm{y}}\right\},
\end{aligned}
$$

Since $-c_{\mathrm{y}}^{-1}(\mathrm{x}, \mathrm{y}) \mathrm{c}_{\mathrm{x}}(\mathrm{y}) \mathrm{g}(\mathrm{x}) \neq 0$ for all $\mathrm{x}$ and $\mathrm{y}$ of interest, the relative degree $r=1$, and the linearization relation is

$u=\frac{v+[f(x)+p(x) d] c_{y}^{-1}(x, y) c_{x}(y)}{-c_{y}^{-1}(x, y) c_{x}(y) g(x)}$

Now, assume $v$ is the output of a PID controller in the form

$$
\mathrm{v}=\mathrm{k}_{\mathrm{P}} \mathrm{e}+\mathrm{k}_{\mathrm{I}} \int \mathrm{e}+\mathrm{y}_{\mathrm{sp}}
$$

where $e=y_{s p}-y$ and $y_{s p}$ is the reference signal, $k_{P}$ is the proportional gain, $\mathrm{k}_{\mathrm{i}}$ is the integral gain.

The control structure of the FL controller is shown in Figure 3.

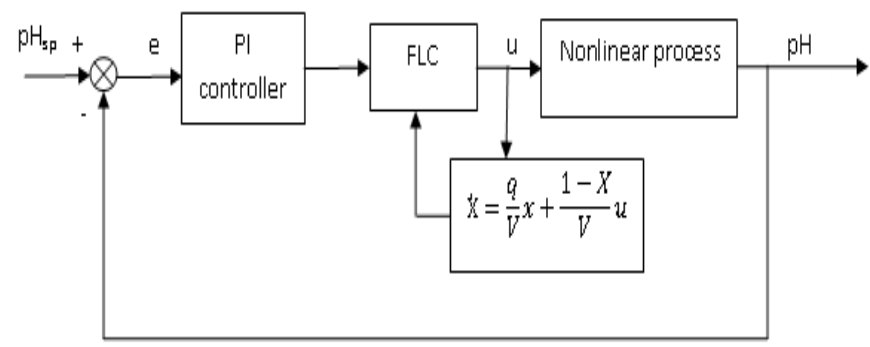

Figure 3: The control structure of the FL controller

\section{ADRC Solution for the $\mathrm{pH}$ Process}

It is shown that the control structure using the feedback linearization method is very complicated. To simplify the control design, ADRC is designed. It is shown that all the nonlinear and time-varying terms under ADRC are components of the total disturbance that need to be estimated and rejected, making the design and structure much more straightforward.

\subsection{Conventional linear ADRC}

We can rewrite the system described in (1) as

$$
\dot{y}=f+b u
$$

where $\mathrm{f}$ is the total disturbance, and $\mathrm{b}$ is the coefficient of the output change rate to the control variable step and varies all through the process. Now, ADRC task is to estimate $f$ in real time and cancel it in the control law, which putting the extended state observer as a choice tool from the modern control theory. Define 
the cases as $\mathrm{x}_{1}=\mathrm{y}$ and $\mathrm{x}_{2}=\mathrm{f}$, where the extended state is represented by $\mathrm{x}_{2}$; then, Eq. (10) rewritten as

$$
\begin{gathered}
{\left[\begin{array}{l}
\dot{x}_{1} \\
\dot{x}_{2}
\end{array}\right]=\left[\begin{array}{ll}
0 & 1 \\
0 & 0
\end{array}\right]\left[\begin{array}{l}
x_{1} \\
x_{2}
\end{array}\right]+\left[\begin{array}{l}
b \\
0
\end{array}\right] \dot{f}} \\
y=x_{1}
\end{gathered}
$$

An ESO can be constructed to estimate the states

$$
\begin{gathered}
{\left[\begin{array}{l}
\dot{z}_{1} \\
\dot{z}_{2}
\end{array}\right]=\left[\begin{array}{ll}
0 & 1 \\
0 & 0
\end{array}\right]\left[\begin{array}{l}
z_{1} \\
z_{2}
\end{array}\right]+\left[\begin{array}{l}
b \\
0
\end{array}\right] u+\left[\begin{array}{l}
\beta_{1} \\
\beta_{2}
\end{array}\right](y-\hat{y})} \\
\hat{y}=z_{1}
\end{gathered}
$$

where $\beta_{1}$ and $\beta_{2}$ represent the gains of the observer.

The total disturbance $\mathrm{z}_{2}$ will be estimated by a well-tuned observer in Eq.(12), and the control law

$$
u=\frac{-z_{2}+u_{0}}{b}
$$

where $\mathrm{u}_{0}$ is a virtual control signal, then Eq.(10) reduced to

$$
\dot{y}=u_{0}+\left(f-z_{2}\right) \approx u_{0}
$$

which can be easily controlled using a proportional controller.

$$
u_{0}=k_{p}\left(r-z_{1}\right)
$$

Here $\mathrm{k}_{\mathrm{p}}$ is the controller gain and $\mathrm{r}$ is the reference signal.

The structure of the ADRC is shown in Figure 4.

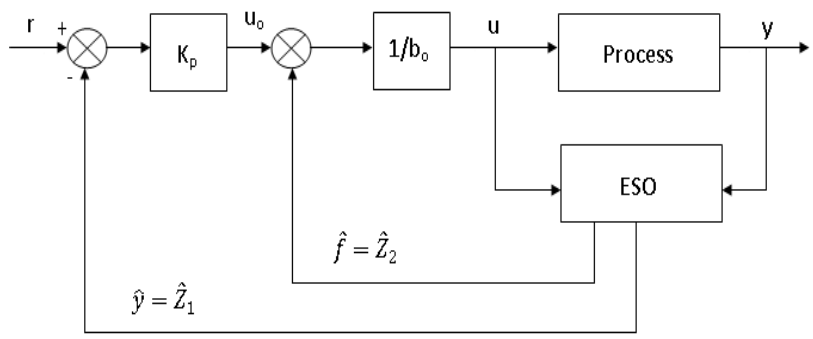

Figure 4: ADRC structure for a first-order process

The gains of the observer are chosen as $\beta_{1}=2 \omega_{\mathrm{ob}}$ and $\beta_{2}=$ $\omega^{2}{ }_{\text {ob }}$ to put the observer poles at $-\omega_{\mathrm{ob}}$. In the same way, the controller gains are selected as $\mathrm{k}_{\mathrm{p}}=\omega_{\mathrm{c}}$ to put the pole of the control loop at $-\omega_{\mathrm{c}}$. $\omega_{\mathrm{ob}}$ and $\omega_{\mathrm{c}}$ are called the observer bandwidth and controller bandwidth, respectively.

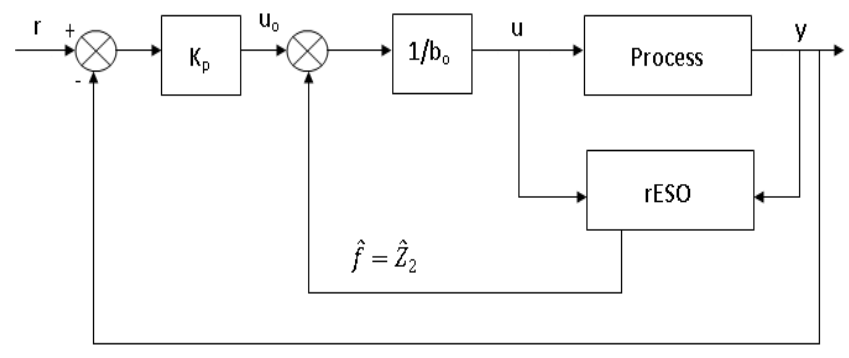

Figure 5: ESO based reduced-order ADRC

\subsection{Reduced-order $A D R C$ (rADRC)}

In the ADRC, a second-order ESO is used to obtain the extended state compensation estimate; however, redundancy occurs when the state's first component can be directly measured [31]. A reduced-order state observer is employed, as shown in Figure 5.

The state observer of reduced-order for $\mathrm{x}_{2}$ is

$$
\dot{\mathrm{z}}_{2}=-\omega_{o b} z_{2}-\omega_{o b} b u+\omega_{o b \dot{\mathrm{Y}}}
$$

where $\omega_{o b}(>0)$ determines the convergent rate of the ESO. To avoid intensifying measurement noises by direct numerical differentiation of signal y in (16), we define a new state as

$$
z=z_{2}-\omega_{o b} \mathrm{Y}
$$

Therefore (16) may be rewritten as

$$
\dot{\mathrm{z}}=-\omega_{o b} \mathrm{z}-\omega_{o b}{ }^{2} y-\omega_{o b} \mathrm{bu}
$$

which combined with

$$
z_{2}=z+\omega_{o b} \mathrm{y}
$$

constitutes the reduced-order ESO. The remaining controller design is the same as those above.

\section{Simulation Results}

A comparison between the performances of the designed FL and ADRC controllers is carried out through simulation. The change in buffer and feed stream flow rate is regarded as a disturbance to the system and shown in Fig. 6. The ADRC parameters are shown in Table 2.

Table 2. ADRC controller parameters

\begin{tabular}{|l|c|c|c|}
\hline ADRC & $\omega_{\mathrm{ob}}=5$ & $\mathrm{~b}=0.05$ & $\omega_{\mathrm{c}}=10$ \\
\hline rADRC & $\omega_{\mathrm{ob}}=0.9$ & $\mathrm{~b}=0.05$ & $\omega_{\mathrm{c}}=10$ \\
\hline
\end{tabular}
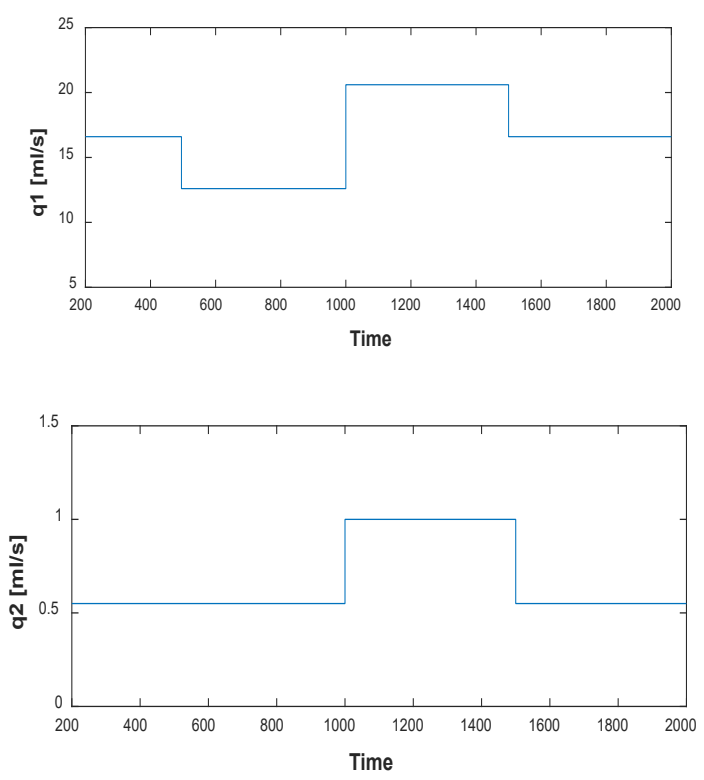

Figure 6: The change of buffer and feed stream flow rate 
There are two cases considered in this simulation.

\section{A. Constant Parameters}

First, let us look at the case of the constant parameter. The efficiency of both disturbance rejection (Figure 7) and setpoint tracking (Figure 8) is examined to evaluate the effectiveness and robustness of the control system. A comparison to the FL controller carried out to illustrate the advantages of the ADRC as well as the rADRC. It can be observed from Figure 7 the superiority of ADRC and rADRC over the FL controller. We can see from Figure 8 that ADRC tracks the change in setpoint very well, and rADRC tracks it even better, while the FL controller shows some overshoot with longer settling time.
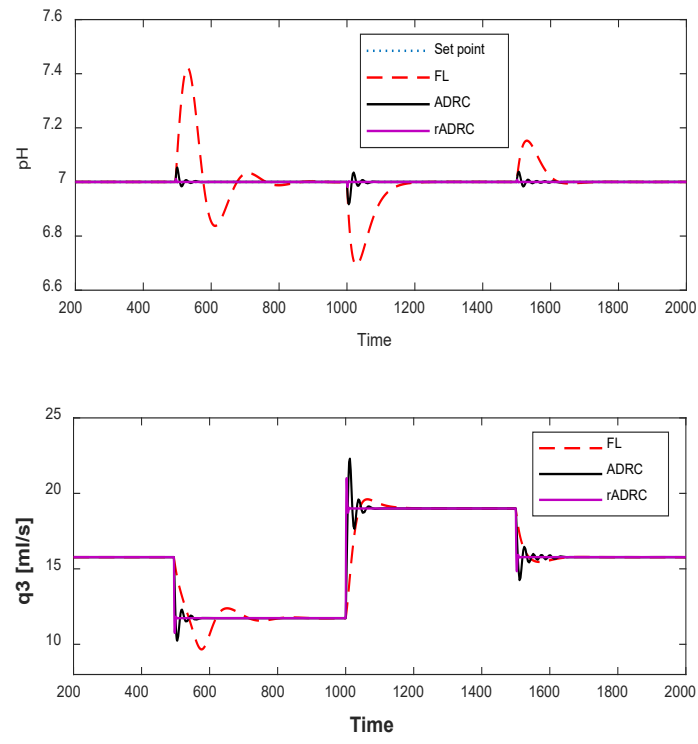

Figure 7: The performance of disturbance rejection
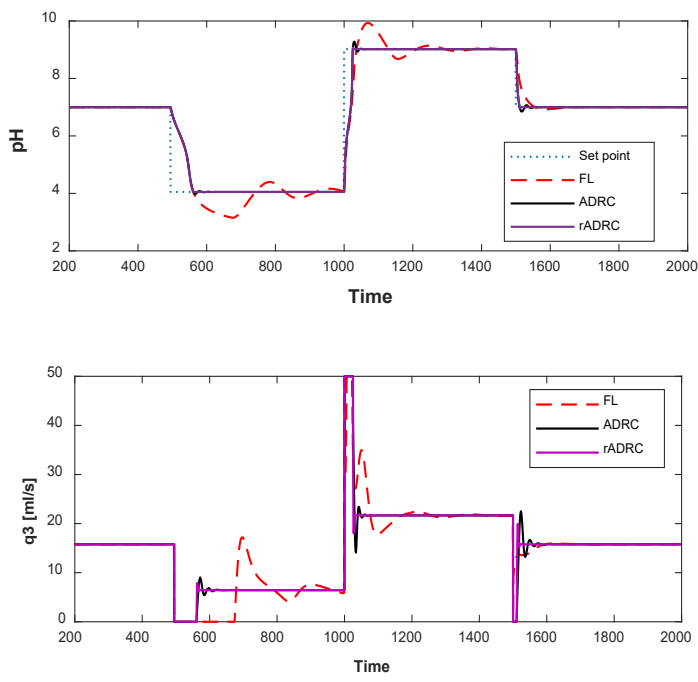

Figure 8: The performance of setpoint tracking

\section{B. Variations in the parameters}

The parameters changes are discussed In this case. They are regarded and handled as a system's internal disturbance. Figure 9 shows the changes in the concentrations of the feed stream.
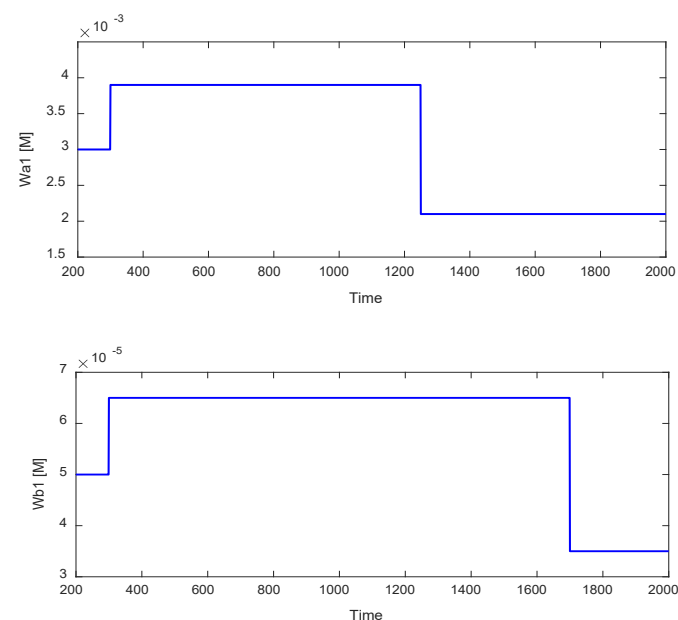

Figure 9: Variations in the concentration of the feed stream

Figure 10 shows the performance of the disturbance rejection, while Figure 11 shows the performance of the setpoint tracking. We can see obviously that ADRC and rADRC are superior to the FL controller.
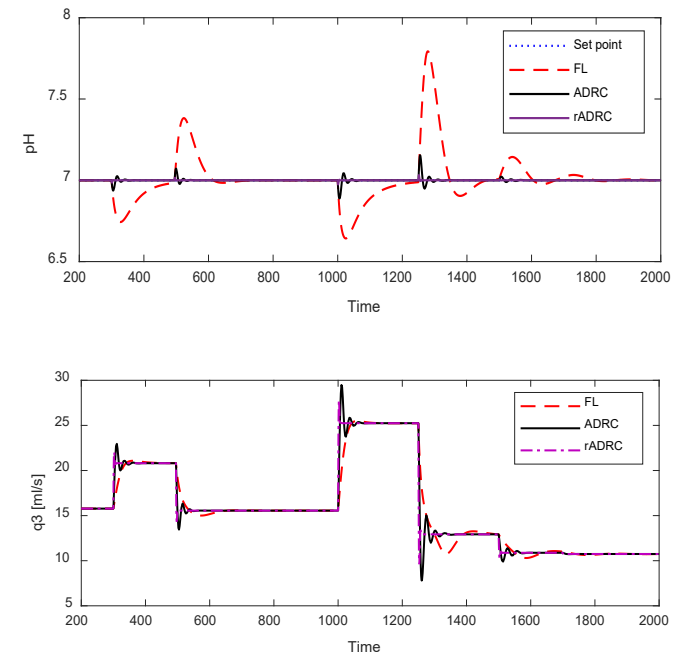

Figure 10: The performance of disturbance rejection with variation in parameters
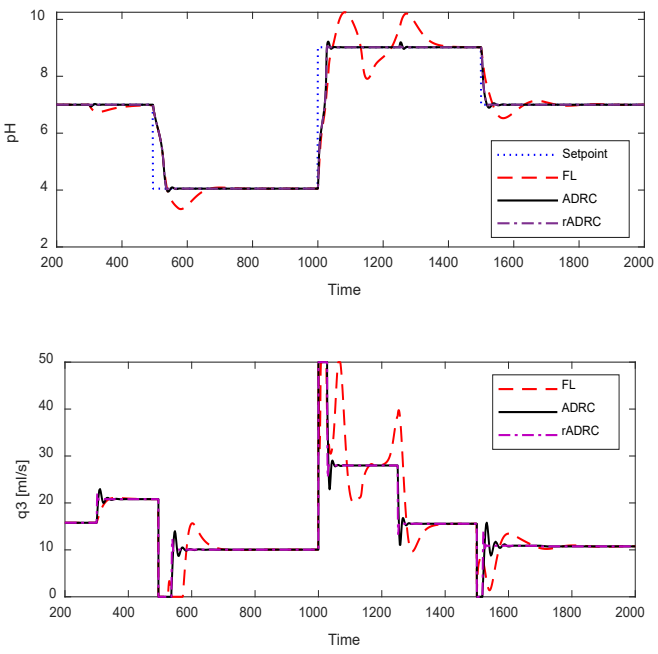

Figure 11: The performance of setpoint tracking with variation in parameters 


\section{Conclusion}

A novel control technique (ADRC) for a $\mathrm{pH}$ process is presented in this paper. ADRC is an excellent solution to the process that needs a high performance controller to overcome the modeling errors and disturbances. ADRC's $\mathrm{pH}$ simulation studies showed a major enhancement over nonlinear FL control. For more analysis, a reduced-order ADRC was designed and proved that it has the most significant performance in regulating the $\mathrm{pH}$ in the existence of the input and external disturbances. The ADRC method is a strong algorithm, particularly in rejection of disturbances. Compared to FL control technique, design and tuning are much more straightforward.

\section{Conflict of Interest}

The authors declare no conflict of interest.

\section{References}

[1] M. H. Eljack, M. B. Musa, W. Tan, "pH Neutralization Process Control Using Linear Active Disturbance Rejection Control." In 2018 IEEE 15th International Computer Conference on Wavelet Active Media Technology and Information Processing (ICCWAMTIP). 205-210, 2018. https://doi.org/10.1109/iccwamtip.2018.8632617

[2] M. A. Henson, D. E. Seborg, "Adaptive nonlinear control of a $\mathrm{pH}$ neutralization process," IEEE transactions on control systems technology, 2(3), 169-182, 1994. https://doi.org/10.1109/87.317975

[3] F. G. Shinskey, pH and PION Confrol in Process and Waste Streams.New York: Wiley, 1973. https://doi.org/10.1016/0013-9327(74)90073-1

[4] G. K. McMillan, pH Control. Research Triangle Park, NC: Instrument Society of America, 1984.

[5] A. Johnson, "The control of fed-batch fermentation processes-A survey," Automatica, 23(6): $\quad 691-705$, 1987. https://doi.org/10.1016/00051098(87)90026-4

[6] R. A. Aguiar, I. C. Franco, F. Leonardi, \& F. Lima. Fractional PID Controller Applied to a Chemical Plant with Level and $\mathrm{pH}$ Control. Chemical Product and Process Modeling, 13(4), 2018. https://doi.org/10.1515/cppm-20180004

[7] R. Vilanova, A. Visioli, PID Control in the Third Millennium: Lessons Learned and New Approaches", Springer, London 2012.

[8] R. A. Wright, C. Kravaris, "Nonlinear pH control in a CSTR," American Control Conference Proceeding, 1540-1544, 1989. https://doi.org/10.23919/acc.1989.4790431

[9] T. K. Gustafsson, K. V. Waller, "Dynamic modeling and reaction invariant control of pH," Chem. Eng. Sci. 38(3): 389-398, 1983. https://doi.org/10.1016/0009-2509(83)80157-2

[10] P. Jutilia, "An application of adaptive $\mathrm{pH}$-control algorithms based on physiochemical modeling in a chemical waste-water treatment plant," Int. J. Control. 38(3): 639-655,1983. https://doi.org/10.1080/00207178308933099

[11] G. Pajunen, "Comparison of linear and nonlinear adaptive control of pHprocess," in Proc. IEEE Control Systems Magazine. 7(1): 39-43, 1987. https://doi.org/10.1109/mcs.1987.1105238

[12] J. R. Panish, C. B. Brosilow, "Nonlinear inferential control," AIChE J., 34(4): 633-644, 1988.

[13] W. C. Li and L. T. Biegler, "Newton-type controllers for constrained nonlinear processes with uncertainty," Ind. Eng. Chem. Res., 29(8): 16471657, 1990. https://doi.org/10.1021/ie00104a012

[14] G. L. Williams, R. R. Rhinehart, J. B. Riggs, "In-line process model-based control of wastewater $\mathrm{pH}$ using dual base injection," Ind. Eng. Chem. Res., 29(7): 1254-1259, 1990. https://doi.org/10.1021/ie00057a029

[15] J. J. E. Slotine, W. Li, Applied Nonlinear Control, 2nd ed., Prentice Hall, Inc., Upper Saddle River, NJ, 1991.

[16] M. H. E. Elameen, M. N. Karsiti, \& R. Ibrahim, "Nonlinear model feedback linearization control strategy of a pH neutralization process," In 2014 5th International Conference on Intelligent and Advanced Systems (ICIAS) (pp. 1-5). IEEE, 20014. https://doi.org/10.1109/icias.2014.6869488

[17] S. F. Graebe, M. M. Seron, G. C. Goodwin, "Nonlinear tracking and input disturbance rejection with application to $\mathrm{pH}$ control," Journal of Process Control, 6(2-3): 195-202, 1996. https://doi.org/10.1016/0959$1524(96) 86054-9$

[18] H. Degachi, W. Chagra, \& M. Ksouri. "Nonlinear model predictive control for $\mathrm{pH}$ neutralization process based on SOMA algorithm." INTERNATIONAL JOURNAL OF ADVANCED COMPUTER
SCIENCE AND APPLICATIONS, 9(1), 391-398, 2018 https://doi.org/10.14569/ijacsa.2018.090153

[19] A. W. Hermansson \& S. Syafiie. "Model predictive control of $\mathrm{pH}$ neutralization processes: a review." Control Engineering Practice, 45, 98-109, 2015. https://doi.org/10.1016/j.conengprac.2015.09.005

[20] J. Chen, Z. Liu, Y. Peng, Q. Guo, "A New Control Method in pH Neutralization Process." Springer, Berlin, 511-519, 2013. https://doi.org/10.1007/978-3-642-38524-7 56

[21] A. Grancharova, J. Kocijan, \& T. A. Johansen, "Explicit output-feedback nonlinear predictive control based on black-box models," Engineering Applications of Artificial Intelligence, 24(2), 388-397, 2011. https://doi.org/10.1016/j.engappai.2010.10.009

[22] M. Heredia-Molinero, J. Sanchez-Prieto, J. Briongos, M. Palancar, "Feedback PID-like fuzzy controller for $\mathrm{pH}$ regulatory control near the equivalence point," J. Process Control, 2014, 24(7): 1023-1037. https://doi.org/10.1016/j.jprocont.2014.05.006

[23] M. H. Dolatabadi, M. N. Monfared, A. Fakharian, "Robust H-infinity control for the $\mathrm{pH}$ neutralization process based on fuzzy models." In: Fuzzy Systems (IFSC), 13th Iranian Conference on, IEEE, 1-6, 2013. https://doi.org/10.1109/ifsc.2013.6675681

[24] J. Q. Han, "Auto-disturbances-rejection controller and its Application, Control and Decision," January, 13(1): 19-23, 1998. (In Chinese).

[25] J. Q. Han, "From PID Technique to Active Disturbances Rejection Control Technique," Control Engineering of China, 9(3): 13-18, March 2002. https://doi.org/10.1109/tie.2008.2011621

[26] J. Q. Han., "Active Disturbance Rejection Control Technique - the technique for estimating and compensating the uncertainties," National Defense Industry Press, 197-270, 2008.

[27] Z. Gao, "Scaling and parameterization based controller tuning," Proceedings of the American Control Conference, Denver, 6: 4989-4996, 2003. https://doi.org/10.1109/acc.2003.1242516

[28] Z. Chen, Y. Wang, M. Sun, \& Q. Sun, "Convergence and stability analysis of active disturbance rejection control for first-order nonlinear dynamic systems," Transactions of the Institute of Measurement and Control, 41(7), 2064-2076, 2018. https://doi.org/10.1177/0142331218794812

[29] J. Ping \& B. Wang. "Development of User-defined Block Library for ActiveDisturbance-Rejection-Control," In 2010 Third International Conference on Information and Computing, Vol. 2, pp. 151-154, 2010. IEEE. https://doi.org/10.1109/icic.2010.132

[30] K. V. Walker, P. M. Makila, "Chemical reaction invariants and variants and their use in reactor modelling, simulation, and control," Ind. Eng. Chem. Process Des. Dev., 20(1): 111 , 1981. https://doi.org/10.1021/i200012a001

[31] R. Yang, M. Sun, Z. Chen, "Active disturbance rejection control on the firstorder plant.” Journal of Systems Engineering and Electronics, 22(1): 95-102, 2011. https://doi.org/10.3969/j.issn.1004-4132.2011.01.012 